\title{
Breeding beef calves using different feeding technologies
}

\author{
Vladimir Trukhachev ${ }^{1}$, Serhii Oliinyk ${ }^{1}$, Vladimir Kozyr $^{2}$, Nikolay Zlydnev $^{1}$, Alexey Pokotilo ${ }^{1}$ \\ 1 Stavropol State Agrarian University, Faculty of Biotechnology, 355017, Zootekhnichesky Lane, 12, Stavropol, \\ Russian Federation \\ ${ }^{2}$ Institute of Grain Crops of the National Academy of Sciences of Ukraine, 49009, st. Vladimir Vernadsky, 14 , m. \\ Dnipro, Ukraine
}

\begin{abstract}
The article presents the findings on the dynamics of the live weight of calves of various breeds in similar climatic conditions in arid regions of the Stavropol Krai of Russia and the steppe zone of Ukraine. It has been established that the live weight of calves of the Hereford, Kazakh white-headed and Kalmyk breeds when raised according to the traditional technology of beef cattle breeding when calves are sucked under cows up to 6-7 months of age, is in relationship with the milk qualities of mothers. At the same time, the live weight of the gray Ukrainian calves was interrelated regarding the live weight at birth and the feeding technology. A positive relationship was shown in the live weight of calves at birth and during their implementation at 15 and 18 months of age. Most effectively animals used pasture fodder in spring and summer. In an arid climate, it is more appropriate to breed specialized cattle belonging to the Hereford breed and then sell them for breeding in other farms in the region.
\end{abstract}

\section{Introduction}

An important source of natural animal protein in the human diet is a beef. The one of the most significant components of the development of animal husbandry in the Stavropol Territory is increasing the efficiency of its production. To obtain high-quality meat, young cattle, whose pasture breeding according to reasonable technological modes contributes to a significant reduction in the cost of the final product, is used [1]. Therefore, the development of scientifically substantiated recommendations for the introduction of innovative technologies for raising young cattle to obtain high-quality beef amid various paratypic (environmental) factors of the Stavropol Krai will contribute to the efficiency of manufacturing this valuable food product in the region. In cattle breeding of highly developed countries, an approximately equal ratio of genotypes of cattle, specifically, $50 \%$ of beef and $50 \%$ of dairy cattle different in the direction of productivity is considered optimal (European standard) [2, 3]. In the Stavropol Krai, this tendency is noticed only on breeding farms of dairy and meat production lines. At the same time, most farms breed dairy cattle, which reduces the efficiency of beef production, due to the fact that young beef breeds reaching slaughter conditions and approximately equal feed costs, often, it is heavier than peers of other breeds in terms of live weight by $15-20 \%$. Therefore, with an increase in the specific weight of meat cattle genotypes in the Stavropol Territory, the conversion of nutrients from the feeding diet into beef will occur more efficiently. Important components of the technology, which can lead to an increase in the efficiency of raising beef cattle, are the provision of a service period of no more than 400 days, which will ensure the output of at least 85-90 calves per 100 cows; the use of balanced feeding rations will increase the conversion of feed, which in turn will ensure that at least 800 grams of average daily live weight gains are obtained when raising young cattle at the level and cost of feed for an increase of $1 \mathrm{~kg}$ of live weight of no more than 10 feed units; the average live weight of young animals when sold for slaughter should not be lower than $450 \mathrm{~kg}$., which will increase the meat content of carcasses to 4.5-4.8 and the yield of high-quality pulp to $85 \%$ [4].

\section{Materials and methods}

When these selection and technological parameters are reached, the efficiency of raising beef cattle in the Stavropol Territory can increase by $18-25 \%$. Important technological elements that determine the achievement of the above goals in the region, according to Dyachenko M. P., et al. (2006), are also: an increase in the terms of pasture maintenance of specialized animals and breeding of breeding stock in the autumn, the achievement of slaughter conditions at 14-15 months of age; the use of technological (feeding and maintenance systems) and selection and genetic (breed characteristics) factors to increase the average daily increase in live weight and 
reduce the time of fattening of young cattle; for the sale of finished products in large settlements, it is necessary to create additional points of primary processing of livestock in different regions of the Stavropol territory, which will allow organizing a closed cycle of beef production. Due to the special importance of beef cattle breeding for the development of animal husbandry in the Stavropol region, the fattening contingent is formed from animals of different genotypes and areas of economic use. Optimization of beef quality parameters with regards to genetic and breed factors in pedigree farms of the Stavropol Krai involves the development of two main directions: pedigree beef cattle breeding to obtain a sufficient number of highly productive bulls for pedigree breeding and the creation of new marketable herds, as well as the creation of new commercial beef cattle herds obtained by industrial crossing to gain crossbred highly productive young animals and their subsequent fattening in order to produce high-quality meat products.

\section{Results}

In the Stavropol Krai, the pedigree resources of specialized beef cattle are represented by three main breeds being Kalmyk, Kazakh white-headed and Hereford. The technology of keeping beef cattle contains elements of grazing in the spring-autumn period, as well as stall keeping of the breeding stock and yield in the winter. The introduction of industrial crossbreeding is the fastest and relatively inexpensive method of increasing the number of beef cattle, while it aims to mate the bulls of specialized beef breeds with lowproductive breeding stock of the main dairy breeds, which in the Stavropol Krai include Black-and-White, Red Steppe and Simmental ones. When complying with the recommended combination of maternal and paternal breeds, it is possible to use the principle of heterosis for 1 or 2 generations. The principle is observed when crossing genetically distant breeds and is manifested in the fact that crossbred bulls especially in the first generation (F1) surpass initial breeds by $8-15 \%$ in meat productivity and at the same time are characterized by better feed conversion by $5-8 \%$. In the Stavropol Krai, yard housing of specialized beef cattle predominates, especially, grazing for Kalmyk and Kazakh whiteheaded cattle, and cubical yard housing for Hereford cattle. Due to the arid climatic conditions, forage production is focused on obtaining mainly winter and spring crops [5].

Among the breed diversity of Ukraine, Gray Ukrainian cattle retain their unique properties. Animals of this ancient breed of cattle are bred in Dnepropetrovsk (experimental farm "Polivanovka"), Kherson (experimental farm "Markeyevo") and Kiev (subsidiary farm "Kiev-Pechersk Lavra") regions. The largest population of the gene pool remains in the experimental farm "Polivanovka" (567 heads in total, including 270 cows).

Earlier animals of this breed were raised and used here according to the technology of dairy cattle breeding, cows were milked and calves were watered by hand. In recent years, all livestock have been kept according to the technology of beef cattle breeding and calves have been grown on suckling until reaching 8 months of age [6-8].

Thus, our study aims to compare breeding calves on manual feeding and on suckling. The findings are of certain interest and relevance for science and practice, as well as for preserving the gene pool. In modern conditions, the issues of effective management of a herd of cattle are rather significant [9]. Consequently, the optimization of the breeding process of young animals in the dairy period will also contribute to an increase in the efficiency of the industry.

The purpose of the research was to compare the effectiveness of breeding specialized beef cattle. The effectiveness was assessed when the bulls reached the live weight at 15 and 18 months of age when growing according to technologies tested in farms.

The growth rate of bulls with different live weight at birth and watering technologies was assessed on the basis of livestock documentation. For the purpose of indepth analysis of the growth rate of gray Ukrainian calves. The study comprised 5 years. On the basis of comparative analysis they were divided into 3 groups by live weight at birth: small (20-21 kg), medium (30-31 $\mathrm{kg}$ ) and large (over $40 \mathrm{~kg}$ ). At regular birth, some of them (odd) were allocated into one group and during the milk period they were drank manually 3 times a day, 1.5 liters of milk, while the others (even) were grown on suckling. The living and feeding conditions for all groups were the same up to 1.5 years. The young calves of Hereford, Kalmyk and Kazakh white-headed breeds were bred according to the technology of beef cattle breeding, young animals were raised on suckling under cows-mothers up to 6-7 months of age. Evaluation of bulls by their own productivity was carried out by rearing up to 15 months of age according to feeding rations that ensured the development of animals in accordance with breed standards. Feed costs per $1 \mathrm{~kg}$ of live weight gain were 6-8 feed units or 8-12 energetic feed units. The study found that, in addition to the exceptional adaptability to the conditions of the steppe zone of Ukraine (climatic and fodder), a characteristic feature of the breeding herd of Gray Ukrainian cattle was high reproductive capacity (97-98 calves per 100 cows) and ease of calving with fluctuations in the live weight of newborns calves from 20 to $40 \mathrm{~kg}$. The coefficient of small fertility (the ratio of the live weight of newborns to the live weight of mothers) was 0.051-0.060, and it was within such limits for 55 years. At the same time, there was a clear seasonality of growth in the autumn-winter period. Out of the 1,692 born heads, the majority (74\%) was of medium size, $15 \%$ small and $11 \%$ large. The calves born small, developed less intensively with manual feeding in comparison with medium-sized and much more with large ones (Table 1).

However, the calves being small at birth by the age of one year and 15 years compared to the analogs of the middle group were grown by the age of 18 months due to compensatory growth (above average daily and relative gains) and had smaller live weight $(-2 \%)$. Compared with large newborns, lagging of small ones 
was more noticeable. Small-born calves on suckling showed greater growth tendency. The absolute gains exceeded the average throughout the entire study (over 1.5 years $+14 \%$ ).

Table 1. Age dynamics of the live weight of bulls, $\mathrm{X} \pm \mathrm{Sx}$

\begin{tabular}{|c|c|c|c|c|}
\hline \multirow{3}{*}{$\begin{array}{l}\text { Age, } \\
\text { months }\end{array}$} & \multicolumn{2}{|c|}{ Live weight, kg } & \multirow{2}{*}{\multicolumn{2}{|c|}{$\begin{array}{l}\text { Live weight gains, from birth } \\
\text { absolute daily, g }\end{array}$}} \\
\hline & \multirow{2}{*}{ Hand rearing } & \multirow{2}{*}{ On suckling } & & \\
\hline & & & Hand rearing & On suckling \\
\hline \multicolumn{5}{|c|}{ Small at birth } \\
\hline newborns & $20 \pm 0.24$ & $23 \pm 0.67$ & - & - \\
\hline 6 & $162 \pm 4.63$ & $184 \pm 7.01$ & 776 & 880 \\
\hline 15 & $327 \pm 12.03$ & $366 \pm 20.20$ & 678 & 751 \\
\hline 18 & $373 \pm 14.20$ & $426 \pm 27.78$ & 643 & 734 \\
\hline \multicolumn{5}{|c|}{ Average at birth } \\
\hline newborns & $31 \pm 0.17$ & $31 \pm 2.35$ & - & - \\
\hline 6 & $166 \pm 1.21$ & $191 \pm 3.77$ & 738 & 874 \\
\hline 15 & $327 \pm 4.01$ & $384 \pm 6.26$ & 648 & 772 \\
\hline 18 & $381 \pm 4.12$ & $426 \pm 10.50$ & 638 & 720 \\
\hline \multicolumn{5}{|c|}{ Large at birth } \\
\hline newborns & $42 \pm 0.31$ & $40 \pm 0.48$ & - & - \\
\hline 6 & $186 \pm 4.36$ & $220 \pm 8.90$ & 787 & 1000 \\
\hline 15 & $347 \pm 10.89$ & $401 \pm 11.80$ & 667 & 796 \\
\hline 18 & $397 \pm 13.77$ & $450 \pm 17.70$ & 647 & 752 \\
\hline
\end{tabular}

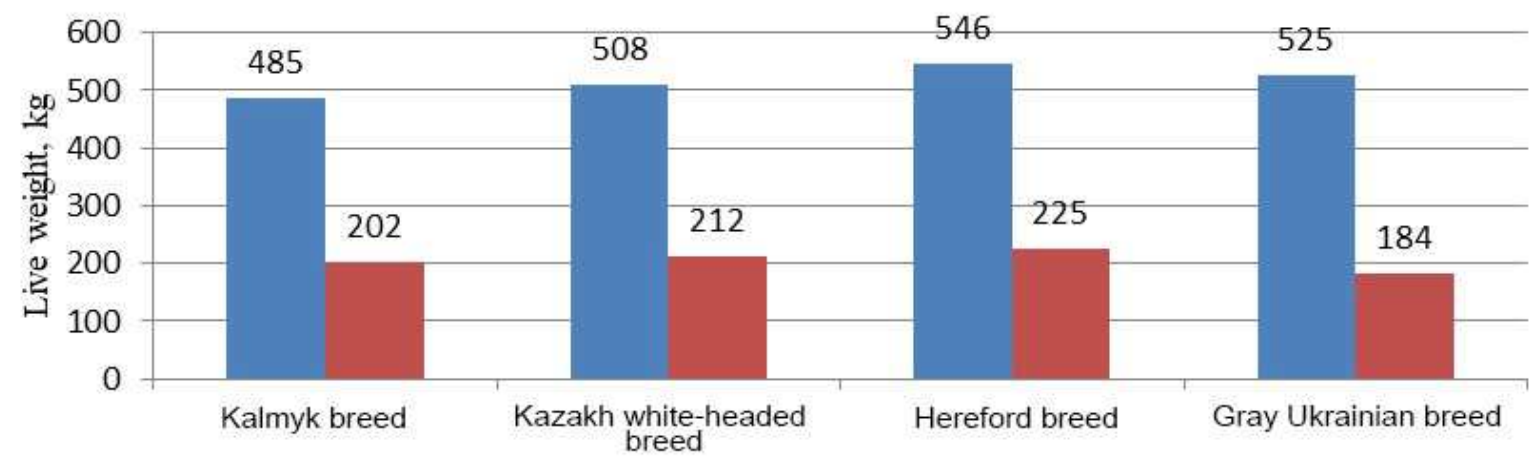

- Cows weight, $\mathrm{kg}$ Milk production, $\mathrm{kg}$

Fig. 1. Milk production of cows of specialized beef breeds

Obviously, in the relict herd of autochthonous gray Ukrainian cattle being an ancient aboriginal breed standing closer to wild ancestors in the evolutionary process [1], the stabilizing form of natural selection was most pronounced, which manifested itself in the strength of the constitution, small yield and mobilization of compensatory functions of the organism, which resulted in the elimination of the growth retardation in the postembryonic period due to excellent adaptation to the local conditions of the south of Ukraine.

By the age of 18 months, the calves assigned to the group of average live weight at birth were slightly heavier than small-born ones when being hand-fed, and the animals on suckling did not differ at all from their analogues $(426 \mathrm{~kg})$. Their average daily gains were
$12 \%$ higher. As a result, by the end of the experiment, they were $45 \mathrm{~kg}$ heavier than their peers raised on hand-feeding. Animals that were born large both with manual feeding and on suckling dominated in all age periods in terms of gain and by 18 months of age in live weight, they were heavier than their peers in other groups. Analysis of the productive qualities of the breeding stock of the Kalmyk, Kazakh white-headed and Hereford breeds showed (Fig. 1) that the average live weight of adult cows increased in general by $4.5 \%$ and $7.0 \%$ as the blood of the Hereford breed changed. The increase in milk production (live weight of suckling calves at the age of 205 days) also occurred with the indicated trend and amounted to $4.7 \%$ and $5.8 \%$, respectively. 


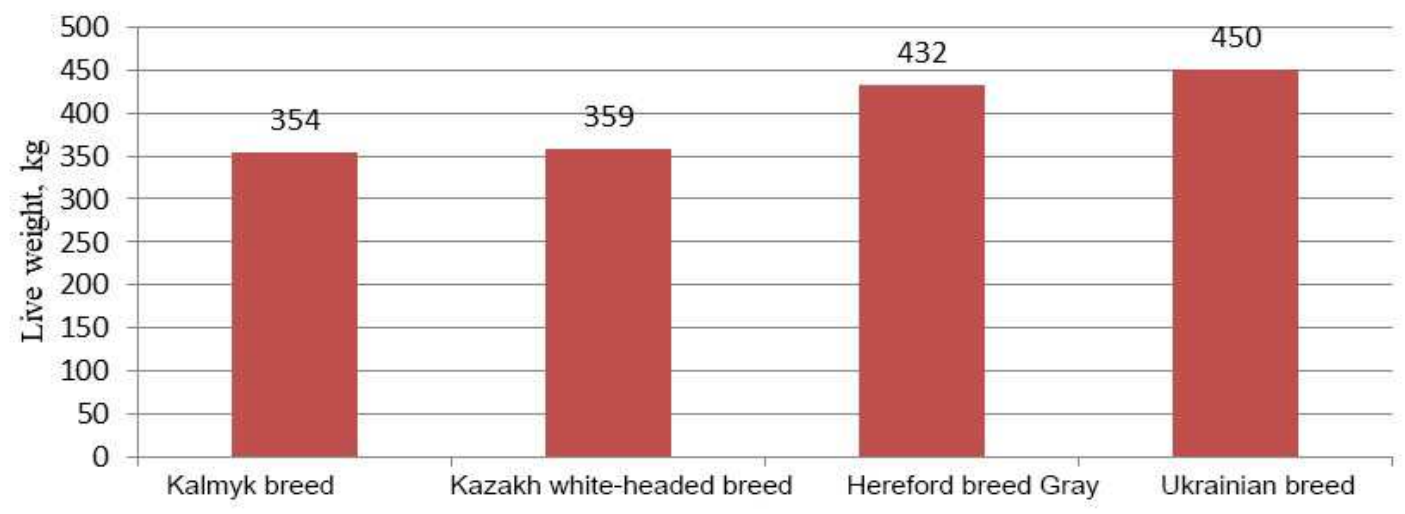

Fig. 2. Evaluation of bulls of various breeds by their own productivity at 15 months of age

The Kalmyk breed was characterized by outstanding adaptive qualities. The reason has not yet been fully understood, while the productive milk qualities of the Kalmyk cows were somewhat inferior to the classic Hereford breed, which was created in much more favorable climatic British conditions. Cows of the gray Ukrainian breed surpassed the cows of the Kalmyk and Kazakh white-headed breeds by 3.35$8.24 \%$, but they were $3.84 \%$ inferior to the Hereford breed.

The results of evaluating 15-month-old bulls of various breeds according to their own productivity show an obvious advantage of animals with Hereford blood (Fig. 2). Thus, purebred Herefords surpassed the peers of other breeds by $18-96 \mathrm{~kg}$ or $4.2-27.1 \%$, which emphasizes the prospects of using genotypes with Hereford blood breeds for the production of beef.

\section{Discussion}

Analysis of domestic and foreign experience in the production of high-quality beef with regards to genetic and breed factors, determined promising directions for improving the technology of beef production and raising beef cattle with respect to optimizing the quality parameters of beef bred in the Stavropol Krai taking into account specific breeds and genotypes.

Assessment of the actual parameters of the beef quality with regards to genetic and breed factors in the breeding farms of the Stavropol Krai proved the effectiveness of state measures aimed to support the development of beef cattle breeding and improvement of the management system of the industry.

The development of a methodology for optimizing beef quality parameters with regards to genetic and breed factors in breeding farms of the Stavropol Krai determined promising directions for increasing beef production in the region for a more complete use of the genetic resources of pedigree beef cattle.

Changes only in the method of using cows and in the technology of growing young stock of the gray Ukrainian breed (on manual feeding and suckling) did not make a significant difference in its live weight, since it was impossible in a short time to change the historically formed conservative combined heredity of gray Ukrainian cattle known as a working meat-dairy direction in the past, as was noted in the studies of A. Bondar (1997). According to Vasilkovsky S. and Fursa N. (2002), the preservation of the gene pool of this breed requires purposeful artificial selection based on the study and control of its pressure, under which the breed has been bred over the past centuries, in order to preserve its characteristic features being small yield, good growth energy, strength, long-growing ability. As L.V. Godovanets pointed out (1986), in the future, there would be an urgent need for this genotype when creating specialized meat breeds and types as well as for improving existing breeds and increasing beef production in industrial crossing, [3].

Thus, when introducing any new method of raising livestock for meat, it is necessary to initially determine the genetic potential of its productivity and compare it with the actual indicator having been already achieved. And if the difference between them is insignificant, and the introduction of a new method (technique) requires large expenses, then it is necessary, first of all, to solve the issues of increasing this potential and to introduce innovations afterwards. In the steppe zone and arid climate, it is advisable to practice lengthening the grazing period of rearing young stock up to 180-200 days, which can significantly reduce the cost of raising animals and increase the efficiency of beef cattle breeding [4].

The effective management of a herd of cattle in the context of industrial technologies for the production of livestock products should regard modern technological innovations that allow achieving break-even production of livestock products [5,6]. A comparative assessment of the breeding of bull calves of various breeds showed the superiority of the Hereford and Kazakh whiteheaded bulls when evaluating their own productivity at the age of 15 months, which emphasizes the prospects of using these genotypes for the production of beef in the steppe zone.

\section{Conclusion}

To organize enterprises for the production of beef in the steppe zone, it is advisable to use animals with the blood of the Hereford breed as a feeding group, which, under conditions of breeding and assessment of their 
own productivity at 15 months of age, surpass the classical aboriginal breeds (Kalmyk and gray Ukrainian) in terms of daily average live weight gains by $161-202$ gr. or $22.1-28.0 \%$.

\section{References}

1. V.I. Trukhachev, N.Z. Zlydnev, S.A. Oleinik Prospects and achievements in the production and processing of agricultural products, Stavropol State Agrarian University (2015)

2. H. J. Amerkhanov Dairy and beef cattle breeding, 6 (2004)

3. B. J. Bagriy Dairy and meat cattle breeding, 8 (2004)

4. S.A. Oleinik Beef cattle breeding in the steppe zone of Ukraine: technology, ethology, economics (Dnepropetrovsk, IMA-pres, 2011)

5. M.P. Dyachenko, I.M. Dunin, K.K. Adzhibekov Milk and meat productivity of cattle breeds in the steppe zone of the Stavropol Territory (Stavropol, Stavropol book publishing house, 2006)

6. A.A. Bondar J. Bulletin of Agrarian Science, 7 (1997)

7. S. Vasilkovsky, N. J. Fursa Animal husbandry of Ukraine, 5, (2002)

8. L.V. Godovanets The influence of changes in the technique of research of gray Ukrainian cattle on some of its economic and biological indicators (Dnepropetrovsk, 1986)

9. V.I. Trukhachev, S.A. Oleinik, N.Z. Zlydnev, V.Yu.Morozov Guidelines for the formation and management of highly productive genetic resources of animal husbandry at the regional level (Stavropol State Agrarian University, Stavropol, 2016) 